\title{
GRAMSCI E OS MOVIMENTOS POPULARES: UMA LEITURA A PARTIR DO CADERNO 25
}

\author{
GIOVANNI SEMERARO*
}

RESUMO: Tendo como base a análise do Caderno 25, nesse texto são destacados os elementos de proximidade e as diferenças entre o significado que Gramsci confere aos "grupos sociais subalternos" e a configuração dos movimentos populares brasileiros e latino-americanos nestas últimas décadas. De um lado, as atenções se concentram sobre as contradições e os riscos aos quais os movimentos populares estão expostos, sobre seu "subversivismo esporádico", suas fragilidades e cooptação. Por outro lado, são colocados em evidência "o valor inestimável das suas iniciativas", seu "espírito criativo", suas peculiares experiências político-pedagógicas e o desenho de um projeto alternativo de sociedade frente à crise que afeta o sistema-mundo atual.

Palavras-chave: Gramsci. Subalternos. Política. Educação.

\section{GRAMSCI AND THE POPULAR MOVEMENTS:}

\section{A READING BASED ON NOTEBOOK 25}

ABSTRACT: Based on the study of Notebook 25, this text analyses the similarities and differences between the meaning that Gramsci gives to the "subaltern social groups" and the configuration of popular movements in Brazil and Latin America in these last decades. On the one hand, our attentions are focused on the contradictions and the risks to which the popular movements are exposed to, on their "casual subversiveness", weaknesses and cooptation. On the other hand, we highlight "the inestimable value of their initiatives, their "creative spirit", their peculiar political-pedagogical experiences and the design of an alternative project of society for addressing the current world-system crisis.

Key words: Gramsci. Subalterns. Politics. Education.

Faculdade de Educação da Universidade Federal Fluminense (UFF). Niterói (RJ) - Brasil. Contato com o autor: <gsemeraro@globo.com> 


\title{
GRAMSCI ET LES MOUVEMENTS POPULAIRES: UNE LECTURE À PARTIR DU CAHIER 25
}

\begin{abstract}
RÉSUMÉ: En ayant comme base l'analyse du Cahier 25, dans ce texte sont détachés les éléments de proximité et les différences entre la signification que Gramsci attribue aux "groupes sociaux subalternes" et la configuration des mouvements populaires brésiliens et latino-américains dans ces dernières décennies. $\mathrm{D}^{\prime}$ un côté, les attentions se concentrent sur les contradictions et les risques auxquels les mouvements populaires sont exposés, sur le "subversivisme sporadique", leurs fragilités et cooptation. D'autre part, sont placés en évidence "la valeur inestimable de leurs initiatives", son "esprit créatif", leurs particulières expériences politico-pédagogiques et le dessin d'un projet alternatif de société devant la crise qui touche le systèmemonde actuel.
\end{abstract}

Mots-clés: Gramsci. Subalternes. Politique. Education.

\section{Premissas para uma interlocução crítica e fecunda}

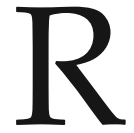

ecorrente e original, a conotação que Gramsci confere ao "popular" em seus escritos é tão marcante que chega a tornar-se critério decisivo para determinar o valor de uma práxis política. Na verdade, antes de ser elaborada nas formas teóricas, essa componente deriva em Gramsci do seu pertencimento ao mundo popular e, principalmente, das opções políticas que o levaram desde cedo a posicionar-se decidida e abertamente em sintonia com as lutas das classes subalternas. Forjada na Sardenha, sua terra natal empobrecida e marginalizada, essa sensibilidade se aprofunda na medida em que Gramsci se envolve intensamente com as reivindicações populares no "mundo grande e terrível" (GRAMSCI, 1996, p. 158, 20/02/1928). ${ }^{1}$

É a partir do "sul", portanto, da óptica "meridional", das rebeliões camponesas, da condição dos operários, dos conselhos de fábrica, da cultura, da educação, da literatura e do teatro "populares", e do partido comunista que os representa, que Gramsci plasma sua militância política e elabora a leitura da realidade. De modo que seu grande interesse pelo senso comum, a religião, as linguagens, o bom senso, o folclore, não figura como curiosidades e aspectos marginais, mas é terreno fértil para descobrir fermentos de uma visão de mundo própria dos subalternos: “Gramsci talvez seja o primeiro marxista ocidental que manifesta um autêntico interesse eminentemente político pela cultura popular, porque nela se manifestava uma produção de significados e interpretações do mundo provenientes das classes subalternas" (CAPUZZO, 2009, p. 49). O pensador sardo, de fato, está convencido de que não há política, transformação social, democracia, revolução e unidade nacional sem o protagonismo do "espírito popular criativo" (GRAMSCI, 1996, p. 57, 19/03/1927). 
Esta visão tem levado diversos analistas a observar que, para Gramsci, "o popular deixa de ser definido por uma série de características internas e por um repertório de conteúdos tradicionais... e passa a ser caracterizado por sua posição frente às classes hegemônicas"' (CANCLINI, 1985, p. 64).

Compreende-se, portanto, porque em Gramsci o conceito de intelectual é recriado a partir da sua estreita "organicidade" com a realidade popular (GRAMSCI, 1975, Q 11, §67, p. 1505-1506). ${ }^{2}$ Porque a educação e a “escola unitária” são interpretadas pela capacidade de se conectar profundamente com o mundo do trabalho e a formação das classes subalternas para tornarem-se "dirigentes" (Q 12, § 2 e § 3, p. 15401551); porque a nova concepção da filosofia da práxis se constrói no terreno das lutas populares (Q 10, II, §16, p. 1255 e Q 10, II, §41, p. 1293) e visa realizar "um progresso intelectual de massa" (Q 11, §12, p. 1385). Mas, também, a hegemonia, o partido, a sociedade civil, o Estado, para Gramsci, só podem obter êxito se tiverem conotação popular, se orientados a organizar uma "vontade coletiva nacional popular" (Q 6, §77, p.745), ${ }^{3}$ não a implementar o domínio de um grupo elitista e corporativo. Por isso, os Cadernos do cárcere se apresentam como um projeto singular de "teoria política popular", um laboratório onde as classes subalternas encontram instrumentos para desenvolver suas posições críticas, para fundamentar sua própria visão de mundo e se preparar para assumir a direção de uma nova concepção de Estado e de sociedade, uma vez que "para construir história duradoura não bastam os 'melhores', são necessárias as mais amplas e numerosas energias nacionais-populares" (Q 9, §96, p. 1160). O reconhecimento dessas forças leva Gramsci a não confundir "popular" com "populismo", entendido este como uma concepção demagógica e paternalista no trato com o povo (Q 11, §1, p. 1367-1385 e Q 9, §135, p. 1197). Longe, também, de qualquer idealização, critica toda visão que mitifica e sacraliza o povo, considerado depositário de valores genuínos e de verdades infalíveis, e se opõe a teorias que o consideram como uma potência unitária, como massa amorfa ou uma genérica "multidão". Ao contrário, nas páginas de Gramsci encontramos sujeitos populares concretos, classes e "grupos sociais subalternos" historicamente "existentes e operantes" que, mesmo com suas ambiguidades e fragilidades, agem como "políticos em ato" e expressam "uma realidade em movimento, uma relação de forças em contínua mudança" (Q 8, §84, p. 990), dentro de um preciso contexto social e econômico, em "assédio recíproco" com a hegemonia dos grupos dominantes. Sem alimentar, portanto, dicotomias simplistas que contraponham autenticidade popular e artificialismo institucional, movimentos populares e partidos, espontaneidade e organização, Gramsci combate tanto o "subversivismo esporádico e desorgânico" (Q 8, §25, p. 957) como o centralismo e o vanguardismo (Q 3, §56, p. 337; Q 13, §36, p. 1634; Q 14, §34, p. 1691-1692), seja o particularismo ou o cosmopolitismo, tornando-se, com isso, um interlocutor crítico e fecundo da realidade vivida pelos movimentos populares brasileiros e latino-americanos. 


\section{O Caderno 25: atualidade e conexões com os movimentos populares}

Sem a pretensão de abarcar a extensão e a complexidade do "popular" em Gramsci, aqui, nos limitaremos a tecer apenas algumas considerações a partir do Caderno 25. Escrito em 1934, no momento mais alto da sua produção intelectual, esse caderno "especial", intitulado "Às margens da história (História dos grupos sociais subalternos)", é organizado em oito parágrafos e condensado em 15 páginas. Embora as questões anotadas nele não apareçam nos planos de estudo delineados no período inicial do cárcere, o conteúdo não é totalmente novo porque Gramsci retoma e reelabora 13 notas do Caderno 1 e do Caderno 3 (escritos em 1930) e a nota 81 do Caderno 9 (1932).

Em um recente artigo, em sintonia com algumas análises já sinalizadas por J. Buttigieg (1999, p. 27-38), ${ }^{4}$ M. Green (2009, p. 53) estabelece uma sugestiva relação entre o conceito "grupos sociais subalternos" utilizado nos Cadernos e o ensaio $\mathrm{Al}$ guns temas da questão meridional (GRAMSCI, 1987, p. 135-165), escrito por Gramsci em 1926, pouco antes de ser encarcerado pelo fascismo. Embora fundamentada e contextualizada, a vinculação dos "subalternos" às questões da Itália meridional focalizada por Green não esgota o conjunto articulado das perspectivas abertas pelo Caderno 25, onde se encontram uma inovadora análise crítica dos "grupos sociais subalternos", critérios para o resgate da sua história e, acima de tudo, indicações para a unificação das suas lutas, em vista da construção da hegemonia popular em torno de uma nova concepção de Estado e de sociedade.

Observando a disposição das notas e a riqueza de dados registrados em um reduzido número de páginas, percebe-se claramente que Gramsci traça um extenso projeto de pesquisa que pretendia desenvolver, abrindo um novo horizonte de compreensão sobre um campo pouco considerado pelas questões clássicas da política e colocado "Às margens da história". Nesse caderno, além de uma incursão no universo das insurgências populares na Itália (§1), de um "pró-memória" de duas linhas sobre Homo faber. História do conceito de trabalho na civilização ocidental (§3), de referências ao protagonismo do poder popular na formação das Comunas italianas (\$4) e da escravidão na Roma antiga (\$6), dedica um intenso parágrafo ao levantamento de Fontes indiretas. As "utopias" e os assim chamados "romances filosóficos" (\$7), um campo imenso de pesquisa onde seria possível descobrir "as aspirações mais elementares e profundas dos grupos sociais subalternos... as condições de instabilidade e de rebelião latente das grandes massas populares de cada época... precursores históricos dos Jacobinos e da Revolução Francesa" (Q 25, §7, p. 2292).

O caráter de projeto preliminar de estudo do Caderno 25 é confirmado também pelo fato de que Gramsci reúne uma notável bibliografia e ensaia algumas análises sobre fatos concretos, em contraposição às interpretações cientificistas predominantes 
(§8) e explicita claramente "critérios metodológicos" (§2) e "critérios metódicos" (§5), na verdade, horizontes epistemológicos onde condensa as orientações fundamentais para balizar suas argumentações e se adentrar nesse complexo e contraditório terreno de investigação. A visão geral desse quadro, como a que deriva do conjunto dos próprios Cadernos, revela que, se é verdade que esses escritos são um canteiro aberto onde "Gramsci deixa aos seus leitores uma grande liberdade de pensar, absorver e se apropriar das suas ideias", de modo a desdobrar novas determinações de acordo com a época e os diversos contextos (GUHA, 2009, p. 40), é verdade também que o autor dos Cadernos enfatiza muito o rigor metodológico e deixa claras suas posições teóricas e políticas.

Como é típico do seu método "filológico", que parte do concreto e "dos particulares" para ascender ao universal e vice-versa (BARATTA, 2004, p. 57 e 110), Gramsci começa o Caderno 25 abordando a notória vicissitude de Davide Lazzaretti, um carreteiro da Toscana que conseguiu galvanizar o descontentamento e a rebelião popular da sua região durante os anos de 1868-1878, período em que os camponeses sofriam as imposições dos liberais para "unificar" a Itália depois do Risorgimento. Conduzidas "pelo alto", as reformas dos novos grupos dominantes marginalizavam as massas populares do sul da Itália, reprimiam rebeliões e não hesitavam em matar líderes "perigosos" como Lazzaretti.

À breve distância dos eventos, a literatura a respeito de Lazzaretti era considerável e Gramsci menciona várias publicações. Logo no início, ao citar um artigo de D. Bulferetti, de 1928, acrescenta: "Bibliografia: Andrea Verga, Davide Lazzaretti e a loucura sensória (Milano, Rechiedei, 1880); Cesare Lombroso, Loucos e anormais", referências imediatamente acompanhadas de um eloquente e fulminante comentário, estrategicamente posto na primeira página: "(este era o costume cultural da época: no lugar de estudar as origens de um acontecimento coletivo, e as razões da sua difusão, do seu ser coletivo, se isolava o protagonista e limitava-se a fazer a bibliografia patológica, muitas vezes partindo de motivos não verificados ou interpretando-os a seu modo: para uma elite social, os elementos dos grupos subalternos apresentam sempre algo de bárbaro e patológico)".

Trata-se de uma crítica cortante às elites e aos seus intelectuais que criminalizavam as sublevações populares e as desqualificavam. Uma consideração que retorna no último parágrafo (\$8) - como a fechar o Caderno 25 com o mesmo motivo -, deixando clara a sua contraposição a uma tendência dominante na cultura do seu tempo, que procurava explicar "cientificamente" (ou seja, naturalisticamente) esse fenômeno de "barbárie". Para Gramsci, ao contrário, "É necessário examinar a tendência da sociologia de esquerda na Itália de ocupar-se intensamente do problema da criminalidade. Seria pelo fato de que à tendência de esquerda havia aderido Lombroso e muitos dos mais 'brilhantes' seguidores que aparentavam então a expressão suprema da ciência, 
influenciando-a com todas as suas deformações profissionais e os seus problemas específicos?". A resposta a essa pergunta pode ser encontrada em Alguns temas da questão meridional, onde aparecem os nomes desses "brilhantes" seguidores de C. Lombroso, pai da criminologia positivista italiana (GRAMSCI, 1987, p. 140). Nesse ensaio de 1926, entre outras considerações, Gramsci ataca a conexão perniciosa entre a ciência positivista e o Partido Socialista, ao qual tais intelectuais pertenciam, o que legitimava ainda mais a política de desqualificação e de repressão aplicada às massas populares do sul da Itália. ${ }^{5}$

Na reconstrução do episódio, Gramsci traz o registro de diversos escritos, mas concentra-se na análise da obra fundamental de G. Barzellotti, ampliada em sucessivas edições, com o título Monte Amiata e o seu Profeta, de 1910, onde se apresenta a progressiva evolução de Lazzaretti, desde a "conversão" que o levou a crer ser descendente de "Manfredo Pallavicino", filho ilegítimo de um rei de França, uma fantasia derivada de um homônimo romance histórico de Giuseppe Rovani, até suas viagens na França e a influência de elementos religiosos e do padre Onorio Taramelli, perseguido por suas ideias republicanas. Diversamente das avaliações superficiais que Bulferetti faz do livro de Barzellotti, Gramsci observa que este "serviu para formar a opinião pública italiana sobre Lazzaretti", encobrindo o mal-estar que existia na Itália depois de 1870 com "explicações reducionistas, individuais, folclóricas, patológicas etc. A mesma coisa tem acontecido mais amplamente com o 'banditismo' meridional e das ilhas". E, de fato, no final desse §1, Gramsci amarra o drama de Lazzaretti a um universo mais amplo, "às 'incursões' dos chamados bandos de Benevento, que são quase simultâneas" ${ }^{6}$

O "lazarettismo", geralmente interpretado na linha do "impressionismo literário" e associado ao folclore popular e a uma patologia perigosa, para Gramsci, ao contrário, é um "drama" típico que "mereceria uma análise político-histórica", pois revela a revolta popular diante das políticas das classes dominantes. A indiferença e a injustiça destas chegam a ponto tal de ignorar que o "assassinato de Lazzaretti tenha sido de uma crueldade feroz e friamente premeditada" para eliminar um perigoso fenômeno em que a "tendência republicana era bizarramente mesclada com o elemento religioso e profético", revelada pela bandeira vermelha de Lazzaretti: "A república e o reino de Deus".

Embora o "lazarettismo" apresentasse características ambíguas, as análises de Gramsci evidenciam agudamente que a mistura de religião e política, para além da "sua popularidade e espontaneidade", manifesta que a "tendência subversivapopular-elementar podia nascer entre os camponeses", cujas "esperanças e expectativas [haviam sido] decepcionadas pelas esquerdas no governo", e, portanto, "na ausência de partidos regulares, se buscavam dirigentes locais que emergiam da própria massa". 
Na interpretação original, concisa e realista que Gramsci oferece desse "drama", saltam aos olhos muitos pontos de contato com os movimentos populares brasileiros que aqui enumeramos de forma resumida: a mescla explosiva de política e religião; o reconhecimento do potencial de resistência dos levantes populares; a criminalização e os estigmas de "patologia" aplicados às suas ações políticas; a modernização imposta pelo alto contra o "atraso" popular; a ilusão de uma "unidade nacional" sem a participação ativa dos camponeses e das massas populares; a decepção destas com as políticas das esquerdas instaladas no poder e a busca de lideranças próprias na falta de partidos; a violência disfarçada e impune das classes dominantes contra os movimentos populares; a ampliação dos horizontes da política e do conceito de "classe" com o resgate da história e da cultura dos "grupos sociais subalternos"; a necessidade de reconstrução da história popular em contraposição às leituras distorcidas difundidas pelos dominantes.

O estudo do "potencial revolucionário dos camponeses" não é novidade no Caderno 25. Era um tema já evidenciado no IV Congresso do Comintern, assim como a questão agrária, a relação do campo com a cidade, a realidade "oriental", quando Gramsci era delegado do PCd'I na URSS, entre 1922-1923. Contudo, é preciso também considerar que os interesses sobre a "questão meridional" são recorrentes nos escritos pré-carcerários ${ }^{7}$ e que Gramsci conhecia numerosos escritos de Salvemini, Nitti, Fortunato, Anzilotti, entre outros, sobre o assunto. Além disso, levando em conta suas posições assumidas no Congresso de Lyon em janeiro de 1926 (CAFAGNA, L. et al., 1990, p. 150), é possível dizer que "O Sul havia se tornado para Gramsci o ponto de vista a partir do qual repensar a história da Itália" (MASELLA, 2008, p. 312).

A análise do "drama" popular representado por Lazzaretti oferece a Gramsci um terreno concreto para formular no §2 os "critérios metodológicos". Na verdade, nesse parágrafo de meia página, Gramsci apresenta o pano de fundo da sua leitura: pela condição "desagregada e episódica" em que versam, "os grupos subalternos sofrem sempre a iniciativa dos grupos dominantes, mesmo quando se rebelam e insurgem". Marcada pela precariedade, toda unificação que eles procuram construir "é continuamente quebrada pela iniciativa dos grupos dominantes". De modo que, para Gramsci, "só a vitória 'permanente' quebra, e não imediatamente, a subordinação". As aspas em "permanente" destacam a necessidade de uma vitória consistente e contínua, mas também o fato de que ela é sempre histórica e ameaçada. E mais, o inciso "não imediatamente" lembra que a "ruptura" nunca é instantânea, mas uma atividade política difícil, demorada e processual. Além disso, embora sua crítica realista o leve a considerar os perigos da fragmentação dos grupos populares subalternos, Gramsci não cai no fatalismo e no determinismo, mas valoriza o potencial destes: "Todo sinal de iniciativa autônoma da parte dos grupos subalternos deveria, 
portanto, ser de valor inestimável para o historiador integral". Assim, em oposição ao reducionismo da ideologia dominante e à manipulação das suas fontes, Gramsci propõe a realização de uma historia "integral", de modo a resgatar a riqueza das inúmeras insurgências populares, a gênese, a complexidade, o jogo das forças em ação, suas conexões com o contexto, o "assédio recíproco" que se estabelece entre os grupos dominantes e os subalternos, o reconhecimento da capacidade de iniciativas desses e as potencialidades que emergem dos fatos históricos.

É o que tenta mostrar no §4: Algumas anotações gerais sobre o desenvolvimento histórico dos grupos sociais subalternos na Idade Média e em Roma. Também nesse caso, Gramsci parte de um ensaio, de Ettore Ciccotti, onde "há algumas referências ao desenvolvimento histórico das classes populares nas nascentes Comunas italianas". De fato, no decorrer das guerras que ocorriam entre estas, a necessidade de defender a própria cidade leva a desenvolver uma consciência política na população. Os combatentes, que permaneciam unidos também em tempo de paz, chegam progressivamente a se constituir em "Sociedades de armas" e a formular seus "estatutos". Com o passar do tempo, além da defesa externa da cidade, essas sociedades se dedicam a "garantir para cada sujeito popular a tutela necessária contra as agressões dos nobres e dos poderosos", fortalecendo sua união com práticas religiosas comuns e ações de mútuo socorro. Todos esses elementos "deságuam na constituição da Comuna". Assim, progressivamente, "O povo se constitui sempre mais em verdadeiro partido político e para dar maior eficiência e centralização à sua ação elege um chefe, 'o Capitão do povo'", que coloca em questão a autoridade estabelecida pelos nobres. De modo que, "Quando o povo não consegue obter das autoridades municipais as reformas reclamadas, faz a secessão... se constitui em assembleia independente, começa a criar magistraturas próprias... a atribuir uma jurisdição ao Capitão do povo, e a deliberar de sua autoridade, dando início (desde 1255) a uma inteira obra legislativa... O povo chega, portanto, a dominar a Comuna, destronando a anterior classe dominante, como ocorreu em Siena... Bologna... Firenze” (Q 25, §4, p. 2286).

Em seguida, enquanto menciona também a importância de questões relativas às raças, à mulher, ao machismo e alerta sobre os perigos inerentes ao método da analogia histórica, com uma rápida síntese, Gramsci traça a evolução do Estado antigo e medieval para o moderno, que "substitui ao bloco mecânico dos grupos sociais uma sua subordinação à hegemonia ativa do grupo dirigente e dominante, portanto abole algumas autonomias que, no entanto, renascem em outra forma, como partidos, sindicatos, associações de cultura".

Nesse §4, a Gramsci importa focalizar particularmente a formação do poder popular no final da Idade Média e seu papel fundamental na constituição das sociedades modernas. Destaca como a progressiva organização da vontade coletiva se torna decisiva na configuração das cidades italianas, na composição das suas leis e 
das suas constituições. Em sintonia com as teorias de Maquiavel, por ele tantas vezes evocado nos Cadernos, mostra como a defesa externa e interna da cidade, a função do "Capitão do povo", a religião e os laços de solidariedade são fundamentais para a constituição do poder político popular e da sua identidade social. No resgate, portanto, da história dos "grupos sociais subalternos" Gramsci estabelece uma conexão com a longa tradição de protagonismo popular que está na base das associações, dos partidos, dos sindicatos, das organizações políticas, da formação do Estado moderno e da democracia. Como veremos mais adiante, é espantosa a proximidade dessa história com as práticas políticas de muitos movimentos populares atuais no Brasil e na América Latina. ${ }^{8}$

Novamente, a análise de fatos concretos oferece a Gramsci elementos históricos para continuar a desenvolver suas reflexões teóricas. Assim, no §5: "Critérios metódicos" Gramsci retoma as considerações do §2 sobre a desagregação dos "grupos sociais subalternos" e a necessidade da sua unificação. Desta vez, porém, explicita a sua proposta. Considerando que "A unidade histórica das classes dirigentes acontece no Estado", em relação orgânica com a sociedade civil, "As classes subalternas, por definição, não são unificadas e não podem se unificar enquanto não chegarem a se tornar 'Estado'". Contrariamente aos que, inclusive dentro do marxismo, desqualificavam o Estado como sendo um aparato meramente "jurídico e formal", Gramsci defende a sua construção pelas "classes subalternas" que lutam para sair da sua condição e buscam a unificação e a hegemonia. No entanto, diversamente das posições liberais que consideram o Estado como um aparelho exterior de caráter "policial" e um "vigia noturno" (Q 5, \$69, p. 604) voltado a garantir a ordem e a propriedade privada com a violência, Gramsci aponta que os subalternos devem criar uma nova concepção de "Estado". Colocado entre aspas, deixa entender que a sua configuração deve ser profundamente diferente da concepção convencional, burocrática, elitista e autoritária. Ao contrário, desenvolvendo uma linha de pensamento que deriva de Rousseau-Hegel-Marx, para Gramsci, “tornar-se Estado” não significa alcançar algo "estático", estabelecer um modelo pré-definido e autoritário, mas quer dizer organizar-se ativamente em uma instituição criada incessantemente pelo agir político de "forças populares", que têm consciência histórica e coletiva. Para sair da condição de "súditos" e de cidadãos formais, os subalternos precisam se unificar e afirmar sua hegemonia ao "fundar novos Estados", assumindo livre e criativamente suas responsabilidades sociopolíticas em um "Estado ético-político" efetivamente democrático e universalizador. ${ }^{9}$

Partindo dessas premissas, Gramsci enumera um conjunto de critérios para construir a história dos subalternos, alertando que tal lista "pode ser ulteriormente especificada". O importante é que nessa construção o historiador seja capaz de "observar e justificar a linha de desenvolvimento em direção à autonomia integral, 
desde as fases mais primitivas, deve perceber toda manifestação do soreliano 'espírito de ruptura"', mostrando como, no enfrentamento dos "inimigos a serem abatidos e na adesão de grupos aliados", as forças inovadoras dos grupos subalternos tornam-se "dirigentes e dominantes" e se unificam em Estado. Desta forma, porquanto "a história dos partidos dos grupos subalternos seja complexa", Gramsci não adere às teorias de um pluralismo amorfo e relativista, que pensa que é possível "Transformar o mundo sem tomar o poder" (HALLOWAY, 2002), mas está convencido de que "Entre os grupos subalternos um vai exercer ou tenderá a exercer uma certa hegemonia por meio de um partido" para liderar o processo histórico-político de ruptura e de criação. A vitória "permanente" dos subalternos, sinalizada no §2, adquire aqui uma estratégia clara: necessidade de ruptura com o sistema implantado pelas classes dominantes, afirmação da "autonomia integral", construção da identidade pelo resgate da própria história, aglutinação em torno de uma organização dotada de hegemonia para unificar as diversas forças populares e criar um novo Estado.

\section{Convergências e diferenças entre os "grupos sociais subalternos" e os "movimentos populares"}

A arquitetura geral do Caderno 25, os temas e os critérios metodológicos nele enunciados estabelecem consideráveis pontos de contato e análise crítica em relação aos movimentos populares brasileiros. Em um dos livros pioneiros sobre Formas primitivas de revolta social, E. Hobsbawm associa Lazzaretti ao movimento "milenarista" dos camponeses da Andaluzia e da Sicília e também ao movimento de Canudos (1966, p. 82) de Antonio Conselheiro (1896-1897), drama imortalizado pela arte literária de Euclides da Cunha na obra Os sertões. Contudo, além desse movimento, embora esmagados e relegados ao esquecimento pela historiografia oficial, só para restar no período entre o final do século XIX e a primeira metade do século XX, poderiam ser mencionadas numerosas insurgências, revoltas e "guerras" de grupos populares que se ergueram em defesa da própria terra e dos seus direitos. ${ }^{10}$ Trata-se, em geral, de expressões explosivas, episódicas, muitas vezes, alimentadas por elementos religiosos e visionários, de grupos "à margem do sistema", diria Gramsci, "[...] em permanente fermento, mas incapazes, como massa, de dar uma expressão unitária às próprias aspirações e necessidades" (1987, p. 154).

Um conjunto de manifestações populares, politicamente mais configuradas, veio se formando em torno da Independência e de instauração da República no Brasil. Embora hegemonizados pelas elites burguesas, muitos desses movimentos evoluíram e se intensificaram durante o processo de industrialização e de urbanização desencadeado a partir dos anos de $1930 .{ }^{11}$ No entanto, foi particularmente no período da ditadura (1964-1985), com a repressão dos partidos e das organizações 
políticas dos trabalhadores, que foram aparecendo na cena política nacional "novos personagens" (SADER, 1988). Foi nesses anos que, do mundo acadêmico e de restritos circuitos políticos e culturais, diversos conceitos provenientes do vocabulário de Gramsci passaram a ser utilizados e reinterpretados também nas organizações político-pedagógicas populares. Ainda que de forma alusiva e inicial, as primeiras aproximações ao pensamento de Gramsci começaram a fecundar escritos de pedagogia, de filosofia, de sociologia, de teologia da libertação, veiculados por muitos intelectuais nos movimentos reivindicatórios de periferia, nas associações de bairro, nas CEBs, nas pastorais sociais, nas inovadoras práticas educacionais populares. Paulo Freire - só para citar a figura mais emblemática de um fenômeno que envolve numerosos intelectuais - refere-se a Gramsci em várias ocasiões e elabora não poucos conceitos a partir do seu pensamento. ${ }^{12}$

Uma leitura mais ampla e aprofundada dos escritos de Gramsci ocorre nos anos de 1980, quando os movimentos populares se reorganizam em torno das lutas pela democratização do país. À semelhança do que Gramsci mostra no Caderno 25, as iniciativas populares desempenham papel fundamental não apenas na elaboração da nova Constituição, mas também na formação de novos partidos, sindicatos e organizações sociais. A multiplicação de estudos e pesquisas que acompanham esse fenômeno reconhecem em Gramsci "o autor que mais contribuiu para as análises e as dinâmicas das lutas e dos movimentos populares" (GOHN, 1997, p. 188). ${ }^{13}$

A partir dos anos de 1990, no entanto, os movimentos populares entram em uma nova fase. Percebem que as lutas pelo "Estado democrático de direito" e algumas conquistas governamentais deixavam intocados o poder das elites e a estrutura econômica do país. Viram que a execração da ditadura e o clamor levantado para exigir substanciais reivindicações sociais eram neutralizados nas tramóias dos jogos parlamentares. Ainda que formalmente democrática, a reestruturação que acabou prevalecendo no Brasil continuou a favorecer as forças conservadoras. Estas, de fato, se rearticularam e conseguiram deflagrar uma pesada ofensiva neoliberal, esvaziando as conquistas populares e implantando um sistema político e representativo que não refletia os reais anseios da população. Neste contexto, mesmo alcançando o poder político central com o consenso popular, partidos de "esquerda" acabaram enredados nas teias do "transformismo" e de uma "revolução passiva" que os manteve longe de estabelecer uma verdadeira hegemonia democrático-popular.

Hoje, portanto, diferenciando-se da tendência de alguns "movimentos sociais" voltados a buscar melhorias e obter benefícios pontuais, os "movimentos populares" se atestam sobre posições "radicais", denunciando as contradições do sistema e o aprofundamento das divisões de classe. Em suas ações resgatam a titularidade permanente do poder popular e reivindicam uma democracia orientada à universalidade dos direitos e à socialização do poder material e simbólico. Nesses 
últimos anos, suas críticas ao projeto não realizado de democracia popular vêm se ampliando e intensificando nas persistentes pressões pelas reformas fundamentais: agrária, econômica, política, ambiental, energética, alimentar, meios de comunicação, educação, saúde, transporte. Suas incansáveis manifestações, juntamente com as lutas contra a burocratização das instituições, a despolitização e as manipulações eleitorais, como observa Gramsci, "pressionam por reivindicações que no seu conjunto desorgânico constituem uma revolução" (Q 13, §23, p. 1603).

De fato, embora perpassados por fragilidades e ambiguidades, dos atuais movimentos populares emerge uma conotação de fundo: não se limitam a combater o neoliberalismo, a "regulamentar" o capital, a promover ações voltadas a "amenizar" a pobreza e as desigualdades com um modelo superado de desenvolvimento, mas se organizam local e mundialmente com a intenção de romper com o capitalismo e construir um projeto alternativo de sociedade e de civilização. Inúmeras atividades desencadeadas pela Via Campesina, o Movimento dos Trabalhadores Rurais Sem Terra (MST), o Movimento dos Atingidos por Barragens (MAB), as organizações indígenas, a Coordenação dos Movimentos Sociais (CMS), o Grito dos Excluídos, o Fórum Social Mundial (FSM), a Rede Jubileu Sul, o Fórum Social das Américas, a Assembleia Popular, a Marcha Mundial das Mulheres, a Consulta Popular, o Movimento Unificado dos Negros, as pastorais sociais, mobilizações de estudantes, práticas de educação popular, protestos, consultas e plebiscitos (Alca, Vale, Tarifas energéticas, Petróleo, Ficha limpa, Propriedade da terra, Clima, entre outros), revelam uma atuação de primeira linha das forças populares no âmbito da sociedade civil. Suas mobilizações, para além de uma "espontaneidade" esporádica, são constituídas por uma grande capacidade político-organizativa em conexão com partidos e sindicatos e chegam a catalisar consideráveis setores das periferias, dos morros, do campo, das cidades, desempregados e precarizados que não se sentem incluídos no restrito círculo da produção, nem representados pela democracia liberal e pelas organizações políticas tradicionais. Com suas formas de fazer política, tais movimentos sinalizam que: "A nova construção só pode surgir de baixo, enquanto toda uma camada nacional, a mais baixa econômica e culturalmente, participe de um fato histórico radical que envolva toda a vida do povo" (Q 6, §162, p. 816).

A "radicalidade" e a capilaridade dessas lutas, de fato, vêm se alastrando cada vez mais na reivindicação pelo controle do território (terra, água, florestas, hidrocarburetos, minérios, biodiversidade, produção agrícola, espaço urbano, entre outros), dos serviços públicos, do sistema financeiro, da produção industrial, da mídia, das funções parlamentares, da pesquisa, da ciência e tecnologia, com vistas à construção de "um novo tipo de Estado" (Q 13, §21, p. 1601). É o que se observa quando diversos movimentos populares começam a deixar claro que não querem "pedir ao Estado o direito à cidadania... mas querem ser os governantes de um 
outro Estado e outra República, uma vez que o Estado republicano contemporâneo tem sido uma estrutura de poder erguida sobre a exclusão" (LINERA, 2007, p. 29). Essa determinação, que revela nas suas atividades "uma consciência 'teórica', criadora de valores históricos e institucionais, de fundadora de Estados" (Q 3, §48, p. 330), acompanhada de uma outra concepção de política, de cultura, de desenvolvimento e de economia, vem se juntando com diversas mobilizações internacionais para enfrentar a "crise estrutural" que afeta o planeta em todos os setores e questiona o modelo predominante de "civilização".

No interior dessas lutas, são muitas as inspirações que os movimentos populares derivam de Gramsci, particularmente, quando se mostram convencidos de que, para sair da condição subalterna, é necessário realizar "o espírito de ruptura e a progressiva conquista da própria personalidade histórica" $(Q 3, \S 49$, p. 333) que se adquire na construção de uma "hegemonia que pode nascer só depois de algumas premissas, ou seja: as grandes organizações populares de tipo moderno" (Q 8, §52, p. 972). No Brasil, tais organizações ainda estão longe de tornar "permanente" sua vitória porque padecem de elementos de fugacidade, precariedade, dispersão, imediatismo e voluntarismo. Ainda que expressiva, de fato, a grande constelação das suas formas não consegue encontrar caminhos para organizar suas forças em torno de um projeto aglutinador e hegemônico em condição de associar as irrupções na "praça" com um projeto econômico-social "realmente progressivo, ou seja, que faz avançar realmente a sociedade inteira" (Q 19, §24, p. 2010-2012), levando-a a passar da esfera individual e corporativa ao âmbito de um Estado “ético-político” (Q 13, §17, p.1583-1584).

No entanto, ainda que caracterizados por debilidades e contradições, é preciso reconhecer que muitos movimentos populares são antenas avançadas que apontam para a realização da "grande política" e introduzem nas suas arenas de lutas horizontes e sensibilidades inéditas, que conduzem a resgatar aspectos pouco considerados nos estudos do pensamento de Gramsci. Na interlocução que os movimentos populares vêm estabelecendo com seus escritos, conferem renovados sentidos à política, à revolução, à democracia, à educação e promovem uma compreensão mais rica na concepção de hegemonia, de Estado, de poder, de "moderno príncipe", chamados a se recriar em outro contexto histórico e a repensar suas relações com os "grupos sociais subalternos", cada vez menos "à margem da história".

\section{Notas}

1. Na referência, acrescentamos a data da Carta, de modo a permitir a localização nas traduções brasileiras.

2. De agora em diante, a referência a essa obra de Gramsci será feita com a letra Q (Quaderni del carcere), seguida do número do caderno, pelo número do parágrafo e das páginas para permitir a localização nas traduções brasileiras. 
3. A propósito, ver Durante (2004, p. 150-169), Luporini (1995, p. 43-51), Frosini (2010, p. 284-296).

4. Ver também: “Subalterno-Subalterni" (in: LIGUORI; VOZA, 2009, p. 827).

5. A mesma análise aparece também em Q 3, §47, onde menciona "as relações que existiram na década de 1890-1900 entre os intelectuais socialistas e os positivistas da escola lombrosiana, obcecados pelo problema da criminalidade, até o ponto de fazer dela uma concepção de mundo ou quase".

6. Em relação a essas questões, Gramsci remete ao importante livro publicado por Nitti (1891), Il socialismo cattolico, onde Lazzaretti é mencionado nas p. 342-344.

7. Cf., por ex., Il Mezzogiorno e la guerra, in "Il Grido del popolo", 1 aprile 1916; Clericali e agrari, in "Avanti", 7 luglio 1916; I contadini e lo stato, in "Avanti", 6 giugno 1918; Operai e contadini, in "L'Ordine Nuovo", 2 agosto 1919; Il Mezzogiorno e il fascismo, in "L'Ordine Nuovo", p. 1-15, aprile 1924.

8. Parte do protagonismo político e teórico dos movimentos populares brasileiros e latino-americanos pode ser visto no livro de Semeraro (2009).

9. Uma análise dessas questões encontra-se no artigo de Semeraro (2008, p. 50-58).

10. Além dos conflitos mais conhecidos na historiografia brasileira, há numerosas "guerras" com características semelhantes às de Canudos. Ex.: Guerra do Pinheirinho (1902), em Encantado (RS); de Vargem Bonita (1917), em Januária (MG); da República dos Anjos (1925), em Pirenópolis (GO); do Caldeirão (1936-1937), em Crato (CE); dos Barbudos (1937), em Soledade e Sobradinho (RS); de Pau de Colher (1938), em Casa Nova (BA); de Quebra-milho (1946-1951), em Centenário do Sul e Jaguapitã (PR); de Trombas e Formoso (1948) em Goiás, entre outras. Na segunda metade do século XX, os levantes populares pela terra se intensificaram, se politizaram mais e se organizaram de forma considerável.

11. A esse respeito, um extenso mapeamento de ações e movimentos populares pode ser encontrado, de forma essencial, no livro de Gohn (2001).

12. Ver Freire (1982, p. 21) e Freire, Gadotti e Guimarães (1986, p. 68). Desde os anos de 1970, dentro e fora do Brasil, há numerosos estudos que registram relações e afinidades entre Gramsci e Freire.

13. Calcula-se que, na década de 1980, praticamente um terço das dissertações e teses acadêmicas fazia referência a Gramsci.

\section{Referências}

CAFAGNA, L. et al. Le tesi di Lione: riflessioni su A. Gramsci e la storia d'Italia. Milano: Fondazione Feltrinelli, 1990. (Quaderni del Fondazione Feltrinelli, n. 39)

BARATTA, G. As rosas e os cadernos: o pensamento dialógico de A. Gramsci. Trad. Giovanni Semeraro. Rio de Janeiro: DP\&A, 2004.

BUTTIGIEG, J. Sulla categoria gramsciana di "subalterno". In: BARATTA, G.; LIGUORI, G. Gramsci da un secolo all'altro. Roma: Riuniti, 1999.

CANCLINI, N.G. Gramsci e as culturas populares na América Latina. In: Coutinho, C.N.; Nogueira, M.A. (Org.). Gramsci e a América Latina. Rio de Janeiro: Paz \& Terra, 1985.

CAPUZZO, P. I subalterni da Gramsci a Guha. In: SCHIRRU, G. Gramsci, le culture e il mondo. Roma: Viella, 2009. p. 41-51. 
DURANTE, L. Nazionale-popolare. In: FROSINI, F.; LIGUORI, G. (Org.). Le parole di Gramsci: per un lessico dei "Quaderni del carcere". Roma: Carocci, 2004. p. 150-169.

FREIRE, P. A importância do ato de ler. São Paulo: Cortez; Campinas: Autores Associados, 1982.

FREIRE, P.; GADOTTI, M.; GUIMARÃES, S. Pedagogia: diálogo e conflito. São Paulo: Cortez, 1986.

FROSINI, F. La religione dell uomo moderno. Roma: Carocci, 2010. p. 284-296.

GOHN, M.G. Teorias dos movimentos sociais: paradigmas clássicos e contemporâneos. São Paulo: Loyola, 1997.

GOHN, M.G. História dos movimentos e lutas sociais. São Paulo: Loyola, 2001.

GRAMSCI, A. Quaderni del carcere, a cura di Valentino Gerratana. Torino: Einaudi, $1975.4 \mathrm{v}$.

GRAMSCI, A. Alguns temas da questão meridional. In: GRAMSCI, A. A questão meridional. Rio de Janeiro: Paz \& Terra, 1987.

GRAMSCI, A. Lettere dal carcere. Palermo: Sellerio, 1996. 2 v.

GREEN, M. Subalternità, questione meridionale e funzione degli intellettuali. In: SCHIRRU, G. (Ed.). Gramsci, le culture e il mondo. Roma: Viella, 2009. p. 53-70.

GUHA, R. Omaggio a un maestro. In: SCHIRRU, G. (Ed.). Gramsci, le culture e il mondo. Roma: Viella, 2009. p. 31-40.

HALLOWAY, J. Cambiar el mundo sin tomar el poder. Buenos Aires: Herramienta; Universidade de Puebla, 2002.

HOBSBAWM, E. I ribelli: forme primitive di rivolta sociale. Roma: Einaudi, 1966.

LIGUORI, G.; VOZA, P. Dizionario Gramsciano. Roma: Carocci, 2009.

LINERA, A.G. El desencuentro de dos razones revolucionárias: indianismo y marxismo. In: Cuadernos del Pensamiento Crítico Latinoamericano, n. 3. Buenos Aires: CLACSO, 2007.

LUPORINI, M.B. Alle origini del "nazionale-popolare". In: BARATTA, G.; CATONE, A. (Org.). Antonio Gramsci e il "progresso intellettuale di massa". Milano: Unicopli, 1995. p. 43-51.

MASELLA, L. Modernizzazione, mezzogiorno e storia d'Italia in Gramsci. In: GIASI, F. (Ed.). Gramsci nel suo tempo. Roma: Carocci, 2008. p. 311-325. 
NITTI, F.S. Il socialismo cattolico. Torino: Roux e C., 1891.

SADER, E. Quando novos personagens entram em cena. Rio de Janeiro: Paz \& Terra, 1988.

SEMERARO, G. Lo "Stato etico" di Gramsci nella costruzione politica dei movimenti popolari. Critica Marxista, n. 1, Roma, gen.-feb. 2008.

SEMERARO, G. Libertação e hegemonia: realizar a América Latina pelos movimentos populares. Aparecida: Ideias e Letras, 2009.

Recebido em 27 de julho de 2011.

Aprovado em 13 de julho de 2012. 